\title{
Synthesis and Characterization of TiC-reinforced Metallic Glass Composite Coatings
}

\section{Ziya Ozgur YAZICI*}

Department of Materials Science and Engineering, Faculty of Engineering, Afyon Kocatepe University, 3200,
Afyonkarahisar, Turkey crossref http://dx.doi.org/10.5755/j02.ms.23362

Received 10 May 2019; accepted 06 January 2020

\begin{abstract}
In this paper, the Co-based metallic glass coatings deposited on soft metal substrates by pneumatic squeezing method were investigated. Also, the effects of $\mathrm{TiC}$ additions $(0-10 \%)$ on the mechanical properties of the coatings were discussed in terms of hardness measurements. Microstructural observations have shown that the coatings with a thickness range of about $20-30 \mu \mathrm{m}$ can be produced as non-porous layers in either entirely amorphous $(0-6 \% \mathrm{TiC})$ or composite $(8-10 \% \mathrm{TiC})$ structures. The glassy and TiC-reinforced glass composite coatings exhibit good adhesion characteristics and form a harder layer with the average hardness values between 1000 and $1600 \mathrm{HV}$ respectively. The hardness measurements evaluated together with XRD and EDX analyses showed that $(\mathrm{Ti}, \mathrm{Ta}) \mathrm{C}$ crystals precipitated in the amorphous matrix are responsible for further increase of the coatings hardness value up to $1600 \mathrm{HV}$. The results also provide clues for mass manufacturing route in one step synthesis of the metallic glass and their composite coatings.

Keywords: metallic glass, composite, coating, microstructure, hardness.
\end{abstract}

\section{INTRODUCTION}

Unlike other materials, cobalt and iron based bulk metallic glasses (BMG), which are collecting the impressive engineering properties on a single body such as high strength [1], hardness [2], corrosion [3] and wear resistance $[4,5]$, and good soft magnetism [6-8], have been a great interest for the potential applications. $\mathrm{Co}_{43} \mathrm{Fe}_{20} \mathrm{Ta}_{5.5} \mathrm{~B}_{31.5}$ and $\left(\mathrm{Co}_{0.535} \mathrm{Fe}_{0.1} \mathrm{Ta}_{0.055} \mathrm{~B}_{0.31}\right)_{98} \mathrm{Mo}_{2}$ glassy alloys may be given as the best examples which are presenting high fracture strength reaching as high as 5185 and $5545 \mathrm{MPa}$ respectively $[7,9]$. These alloys also have high hardness values between $1200-455 \mathrm{Hv}$, but they can only be produced as a rod with a diameter of less than $2 \mathrm{~mm}$. Although minor $\mathrm{Cu}$ and $\mathrm{Si}$ additives can be applied to improve the glass forming ability of the $\mathrm{Co}_{43} \mathrm{Fe}_{20} \mathrm{Ta}_{5.5} \mathrm{~B}_{31.5}$ alloy [10], the utilization of these alloys still meets with some difficulties waiting to be solved due to the various limiting factors in their production routes. For this reason, researchers are trying to utilize the rare properties of these glasses as a coating material by applying on the surface of a substrate [11-14]. Producing an amorphous coating layer on relatively inexpensive substrates, instead of casting the forms with thick-sectioned, may offer opportunities for novel commercial application of metallic glass (MG) alloys.

Metallic glassy alloys have been applied on the substrate surfaces by various coating methods including explosive welding [15], high-velocity oxygen fuel spraying [16], sputtering [17] and laser cladding [18]. Inoue et al. [13] reported that an amorphous coating having the thickness of about $100-200 \mu \mathrm{m}$ which has a compact, smooth and dense morphology obtained on the steel substrates by using plasma spraying. Cheng et al. [19] successfully used wirearc spraying method where a spray of atomized molten droplets used to coat the metallic substrates with a glassy layer. Branagan et al. [20] also prepared metallic glass coated samples by thermal spraying methods (plasma, HVOF) and investigated the wear behavior of the glassy coating. In these examples, researchers have reported acceptable results against various conditions by examining the wear behaviour and hardness properties of metallic glass coatings.

In the past, piston and anvil method was designed by Pietrowsky [21] and it was used for producing thin amorphous foils [22-24]. If this method will be considered for industrial high-speed productions, this technique may have a chance to open an application field in the surface treatments for miniature parts. In this study, aluminum and steel plates were selected as a substrate owing to their low hardness and inferior tribological properties, and Co-based metallic glass coatings were prepared by a simple pneumatic coating apparatus to obtain glassy coating layer on small substrates. Also, the effects of $\mathrm{TiC}$ additions on the properties of the coatings were evaluated in the terms of the microstructure and hardness properties of the samples.

\section{EXPERIMENTAL DETAILS}

Pure metallic and TiC powders having the purity above $99 \%$ were used for the master composition. Master alloys of $\mathrm{Co}_{42} \mathrm{Cu}_{1} \mathrm{Fe}_{20} \mathrm{Ta}_{5.5} \mathrm{~B}_{26.5} \mathrm{Si}_{5}$ with $\mathrm{TiC}$ additions $(0-10$ wt. \%) were produced by arc melting (150 A) under protective atmosphere ( $\left.\mathrm{P}_{\text {vacuum }}: 10^{-2} \mathrm{mbar}+\mathrm{P}_{\text {Argon }}: 1 \mathrm{~atm}\right)$. Melting procedures were performed at least three times for the purpose of the compositional homogeneity. Aluminum and steel plates $(10 \times 10 \mathrm{~mm})$ were selected as substrate materials. Before the coating process, the substrates were blasted by abrasive papers (P400-800) and degreased by

\footnotetext{
* Corresponding author. Tel.: +90-272-2281423; fax: +90-272-2281422.

E-mail address: zyazici@aku.edu.tr (Z. O. Yazici)
} 
acetone, then dried in air. The substrate to be coated was placed in a cavity on the inner surface of one of the two copper piston surfaces where the collision occurs. The other copper piston has a flat surface. An appropriate amount of master alloy piece was melted by arc melting, and then the pistons driven by pneumatic pressure of 5 bar were moved quickly to squeeze the melt between the two cold surfaces. Melting and squeezing operations of the alloys were satisfied at 150 Amps under argon atmosphere. During the squeezing process, the appropriate amount of master alloy is simultaneously compressed by a speed of about $400 \mathrm{~m} / \mathrm{s}$ between the two pistons. Hereby, the molten material has been both solidified by rapid heat transfer, and welded by compression. Fig. 1 a shows the flat melting reservoir and squeezing process used to produce a thin coating layer in this study. The cross sections of the samples after polishing were investigated by scanning electron microscopy (SEM, LEO $1430 \mathrm{VP}$ ) for controlling interface properties and the microstructure observations. X-ray powder diffraction with $\mathrm{Cu}-\mathrm{K} \alpha$ was performed to ascertain amorphous coating layer and crystalline phases in the coating before and after the incorporation of TiC additions. The supercooled liquid and glass transition regions were also verified by DSC Netzsch STA $409 \mathrm{Pc} / \mathrm{Pg}$ at $0.33 \mathrm{~K} / \mathrm{s}$. Measurement conditions of microhardness tests (Shimadzu HMV-2L) were adjusted for a load of $100 \mathrm{~g}$ at $15 \mathrm{sec}$. Abrasive wear tests were performed by a pin-abrasion apparatus with a sliding speed of $0.2 \mathrm{~m} / \mathrm{s}$ up to a distance of about $700 \mathrm{~m}$ under a load of $2.1 \mathrm{~N}$ [28]. The schematic representation of the test configuration is shown in Fig. 2. The wear rate was calculated from weight loss measurement. Weight data were converted to volume loss using density of the samples. The densities of the samples were measured by Archimedes method.

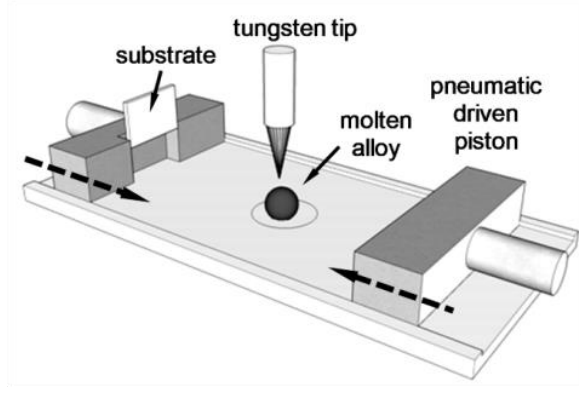

a

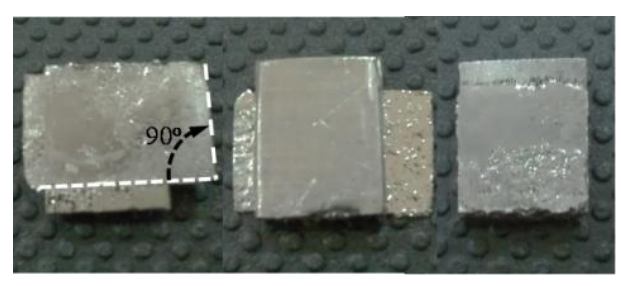

b

Fig. 1. $a$-schematic of piston-anvil process; $b$-as-coated samples produced by this process

\section{RESULTS AND DISCUSSION}

Fig. $1 \mathrm{~b}$ shows the photographs of Co-based metallic glass coated samples. When the pistons were collided head on with a way to overlap their surfaces, the resulting coatings can adhere to the surface of the aluminum substrate. It is interesting to note that the shapes of the coatings obtained spontaneously with a rectangular shape after hitting the pistons rather than a squeezed elliptical, despite the melt with a cylindrical shape during melting.

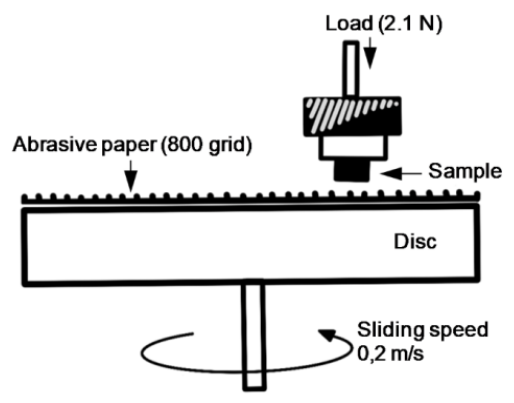

Fig. 2. Schematic illustration of the pin-abrasion apparatus

Microstructures of the coated steel and aluminum substrates are given in Fig. 3 a, b. According to SEM micrographs of the samples, Co-based MG coatings are dense, pore-free $(<0.6 \%$.), and well-adhered to substrates and have smooth exterior surfaces. On the other hand, the interface of the coating on aluminum appears to be rougher because the aluminum substrate is a relatively soft material and has a low melting temperature. A more uniform interface is obtained in the case of a steel base. In addition, it is observed that some interfused aluminum inclusions found in the coating body due to the melting of the aluminum chips which have been formed during surface preparation of the substrates before coating. Meanwhile, the thicknesses of the coatings produced in this study were found to be between $20-35 \mu \mathrm{m}$.

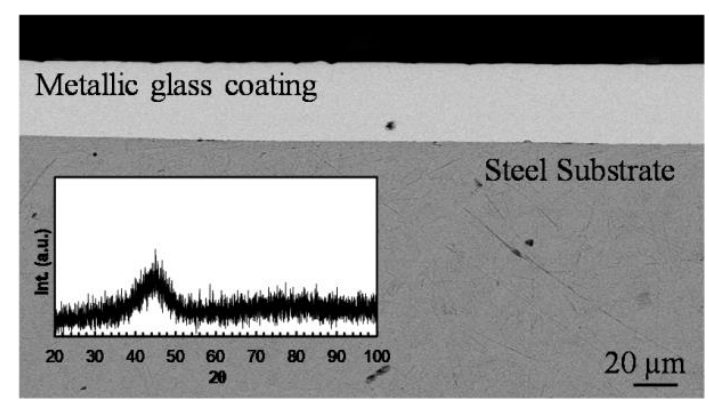

a

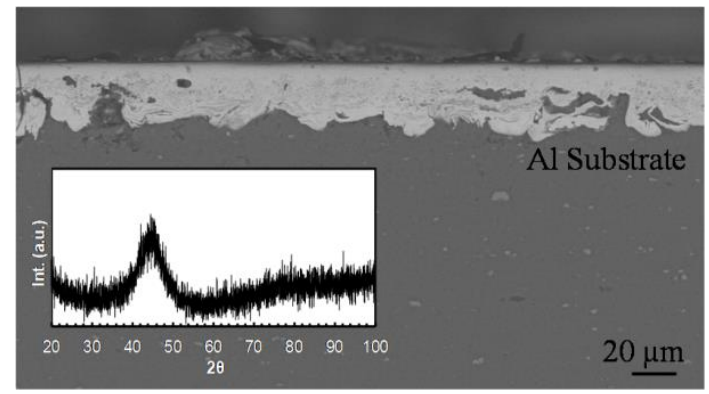

b

Fig. 3. SEM micrographs and XRD patterns of the coatings without $\mathrm{TiC}$ addition solidified on: $\mathrm{a}$-steel; $\mathrm{b}$-aluminum substrates

XRD patterns of the coatings on steel and aluminum substrate are depicted by insets of Fig. $3 \mathrm{a}$ and $\mathrm{b}$ respectively. It can be clearly observed that the patterns of 
the coatings on both substrates do not contain any crystalline peaks. This implies that the molten alloy was successfully solidified with an amorphous structure at an appropriate cooling speed after the squeezing process.

XRD patterns of the TiC-reinforced coatings are shown in Fig. 4. The XRD results clearly show that the structures of reinforced coatings with $1-6 \%$ TiC consist entirely of the glassy phase. From this point of view, it is understood that $\mathrm{TiC}$ can be dissolved up to $6 \mathrm{wt} . \%$ and participated in the amorphous matrix structure without causing any significant crystallization. However, the intensity of the TiC peaks which are superimposed on the amorphous pattern increased in connection with the further increase in the amount of $\mathrm{TiC}(8-10 \%)$ added to the initial composition of the master alloys. Although $\mathrm{TiC}$ powders with the size of about 30 microns were used in the starting compositions, it was observed in Fig. $5 \mathrm{~b}$ that the microstructure of the coating with $8 \%$ TiC contained finely dispersed $\mathrm{TiC}$ crystals with submicron sizes. This suggests that the starting TiC particles experience the dissolution and recrystallization phenomena after melting and rapid solidification processes. Another sign of this issue was determined by the EDX studies on the crystals observed with white color in the microstructure. From the EDX analysis given in Fig. 5 d, white crystals were found to be rich by $\mathrm{Ti}$ and $\mathrm{Ta}$ elements and poor by $\mathrm{Co}$ and $\mathrm{Fe}$ elements. It is well known that $\mathrm{TiC}$ and $\mathrm{TaC}$ have the same cubic structure and they can form a cubic continuous solid solution [25]. With the light of these data, it is normal to be in an assessment presenting the dissolution and recrystallization phenomena, which Ta element present in the base alloy composition may enter to the crystal structure of recrystallized $\mathrm{TiC}$ during the solidification process. While this was the case with $8 \% \mathrm{TiC}$, the coating with $10 \% \mathrm{TiC}$ involved coarser crystals $(3-10 \mu \mathrm{m})$ of the same phase and these crystals precipitated with disorderly distribution within the remaining amorphous matrix.

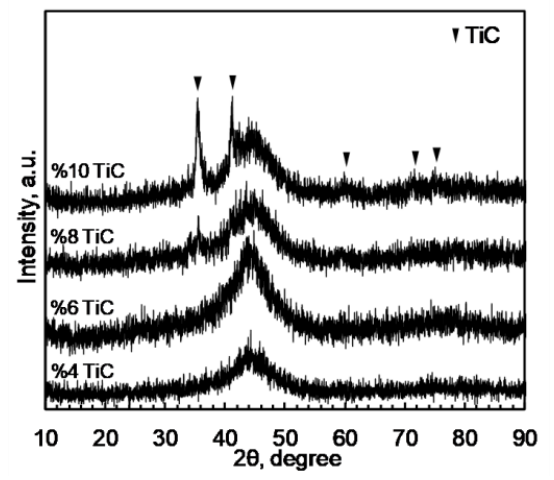

Fig. 4. Precipitation of TiC crystals within the amorphous matrix

Adhesion properties were evaluated by Vickers indentation, to investigate qualitatively the delamination behavior of the coatings. This is is mainly applied to the systems of brittle coatings bonded to ductile substrates [29]. Vickers indent traces (Fig. 6) showed that coatings on the aluminum substrates were durable without any radial cracks, ring cracks and delamination, up to HV0.3 (2.942 N) loading. But loading at HV0.5 (4.903 N) caused a crack with a ring shape around the indent without any spallation from the substrate. The coatings collapsed down due to the deformation of the soft aluminum substrates. This is thought to be the cause of the ring cracks under high loading (>HV0.5) conditions. The absence of spallation was considered to indicate that the coating was bonded metallurgical rather than physical.

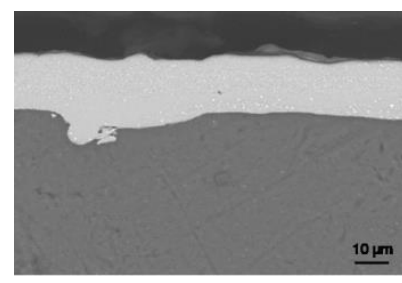

a

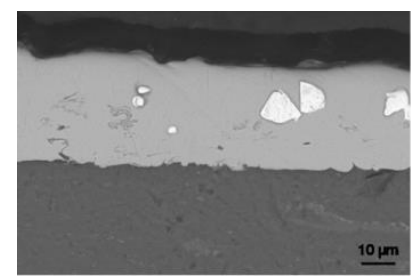

c

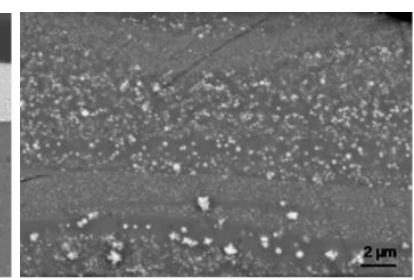

b

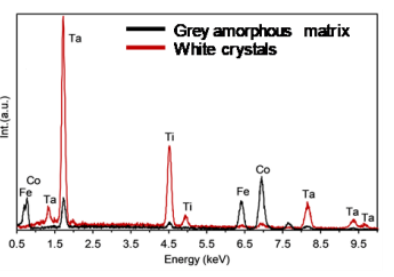

d
Fig. 5. SEM micrographs of the cross sections of the coatings containing: $\mathrm{a}, \mathrm{b}-8 \% \mathrm{TiC} ; \mathrm{c}-10 \% \mathrm{TiC} ; \mathrm{d}-\mathrm{EDX}$ analysis of the white crystals compared with the grey amorphous zone

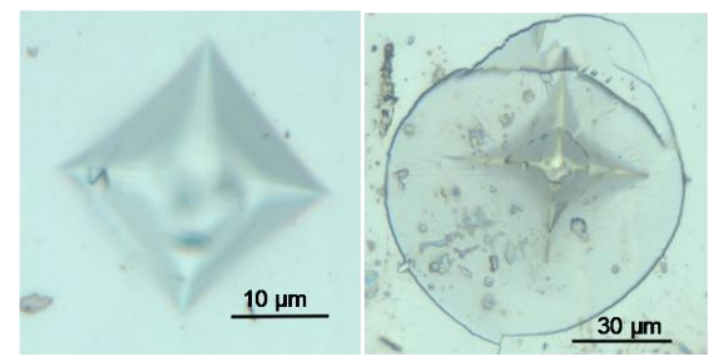

Fig. 6. Vickers indents obtained by loading: a-2.942 N; $\mathrm{b}-4.903 \mathrm{~N}$ forces at the surface of the $8 \%$ TiC-reinforced coating

Fig. 7 represents the average hardness values of the fully amorphous and $8 \% \mathrm{TiC}$ reinforced coatings on aluminum and steel substrates. It is well known that traditional steel and aluminum alloys are relatively soft materials which sometimes may not have sufficient surface resistance to the severe mechanical and corrosive conditions. In this study, the softness of the aluminum and steel substrates are also verified and the average hardness values were measured as 72 and $143 \mathrm{HV}$ respectively. Besides, the amorphous coatings containing $\mathrm{TiC}(0-6 \%)$ exhibit higher hardness values between 900-1100 HV (Fig. 7 a, b). In addition, when the composite coating was produced by the addition of $8 \% \mathrm{TiC}$, the average hardness of the coating was reached to the highest value of about $1600 \mathrm{HV}$ (Fig. 7 c). Apparently, the further increase in the hardness of the coatings with composite structure results from the crystalline precipitates, since no other phase was detected in the composite coatings, except ( $\mathrm{Ti}, \mathrm{Ta}) \mathrm{C}$ precipitates and amorphous phase. Therefore, the average hardness values of the sample containing $10 \% \mathrm{TiC}$ were measured over a wide range between 1000 and $1900 \mathrm{HV}$ which are the values for amorphous phase and TiC particlerich zones respectively. 


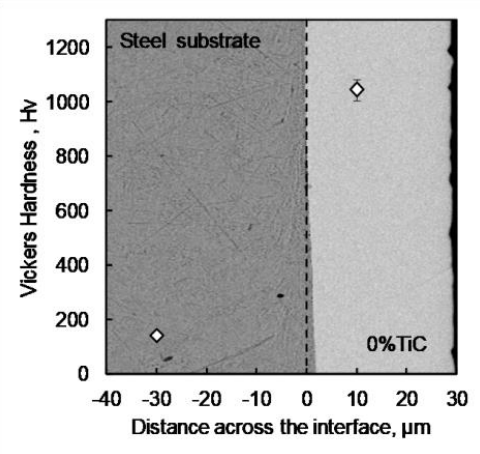

a

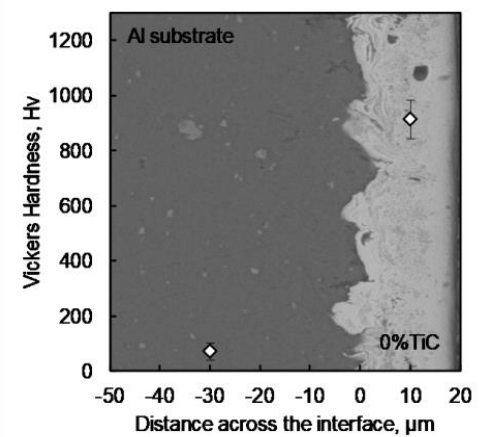

b

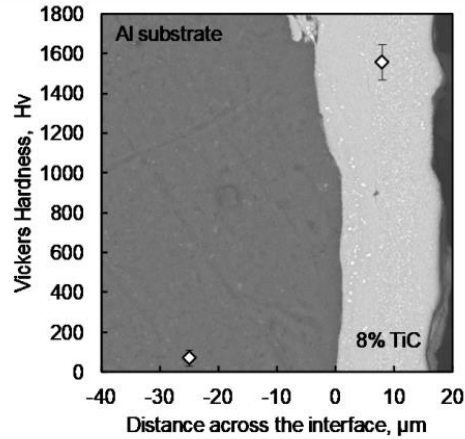

c

Fig. 7. Vickers hardness values of the reinforced metallic glass coatings on steel and aluminum substrates: $a, b-$ metallic glass; $c-8 \%$ $\mathrm{TiC}$

Besides, Rabinowicz [26, 27] proposed an equation relating the volume loss $(\mathrm{V})$ with the hardness of the homogenous sample during the wearing, as shown in Eq. 1:

$V=\frac{\hat{\mathrm{k}} P L}{H}$

where $k$ is the wear coefficient; $P$ is normal load; $L$ is the sliding distance and $H$ is the hardness of the coating. From the Eq. 1 wear rate will vary inversely with the hardness of the coating. Therefore, it can be also suggested that the wear loss of the reinforced coatings will decrease due to the increase in hardness values. Fig. 8 shows measured volume loss of the aluminum substrate and TiC-reinforced samples as a function of sliding distance under constant loading conditions. The results of the wear tests clearly demonstrate that when the TiC content was increased, significant decrease in wear losses was observed. These reductions in wear losses can be attributed to the hardening of the alloys by TiC additions. Thus, these hard coatings can carry the soft substrates to the enhanced surface behaviors which make them attractive for wear applications.

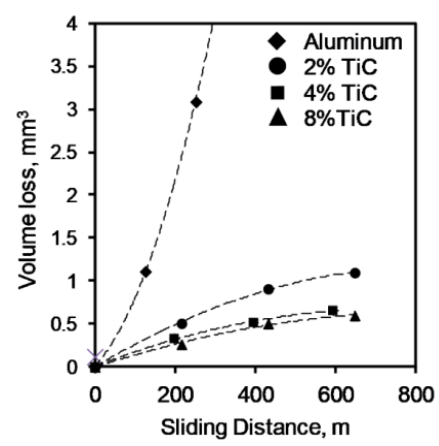

Fig. 8. Abrasive wear behaviors of aluminum substrate and TiCreinforced samples as a function of sliding distance

In this study, Co-based metallic glass and metallic glass composite coatings were produced by means of a pneumatic compression effect. With this technique, it has been shown that metallic glass composite coatings with a high hardness which are intended to be produced by a fast production route and useful for various industrial parts in miniature sizes, can be developed by in-situ crystallization without the need of any heat treatment.

\section{CONCLUSIONS}

The Co-based fully amorphous and TiC-reinforced composite coatings were successfully manufactured without porosity by pneumatic squeezing method and were investigated by means of microstructural features and hardness. The average hardness values of the metallic glass coating were measured between the values of $900-1100 \mathrm{HV}$ in the cross-section of fully amorphous coating regions. In addition, the hardness values of the coatings including finely precipitated crystals were increased as the fraction of $\mathrm{TiC}$ added to the master alloy was increased. In addition, the starting $\mathrm{TiC}$ particles added to the master alloy experienced the dissolution and recrystallization phenomena after melting and rapid solidification processes respectively. Ta element from the alloy composition enter to the crystal structure of recrystallized $\mathrm{TiC}$ during the solidification to form (Ti, Ta)C precipitates. Because of the wear behavior of a material is related to their hardness, thus, these hard coatings can carry the soft substrates to the enhanced surface behaviors which make them attractive for wear applications.

\section{Acknowledgments}

This study was supported by The Coordination Department of Scientific Research Projects, Afyon Kocatepe University, Turkey, (Grant Number: 18.KARiYER.199), which authors gratefully acknowledge.

\section{REFERENCES}

1. Wang, J., Li, R., Hua, N., Zhang, T. Co-based Ternary Bulk Metallic Glasses with Ultrahigh Strength and Plasticity Journal of Materials Research $26(16)$ 2011: pp. 2072-2079.

https://doi.org/10.1557/jmr.2011.187

2. Basu, A., Samant, A.N., Harimkar, S.P., Majumdar, J.D., Manna, I., Dahotre, N.B. Laser Surface Coating of $\mathrm{Fe}-\mathrm{Cr}-$ Mo-Y-B-C Bulk Metallic Glass Composition on AISI 4140 Steel Surface and Coatings Technology $202(12)$ 2008: pp. 2623-2631. https://doi.org/10.1016/j.surfcoat.2007.09.028

3. Burkov, A.A., Chigrin, P.G. Effect of Tungsten, Molybdenum, Nickel and Cobalt on the Corrosion and Wear Performance of Fe-Based Metallic Glass Coatings Surface and Coatings Technology 351 2018: pp. 68-77. https://doi.org/10.1016/j.surfcoat.2018.07.078

4. Chu, Z., Yang, Y., Chen, X., Yan, D., Huang, D., Lei, W., Liu, Z. Characterization and Tribology Performance of Fe- 
based Metallic Glassy Composite Coatings Fabricated by Gas Multiple-Tunnel Plasma Spraying Surface and Coatings Technology 292 2016: pp. 44-48. https://doi.org/10.1016/j.surfcoat.2016.03.024

5. Yoon, S., Kim, J., Kim, B.D., Lee, C. Tribological Behavior of B4C Reinforced Fe-base Bulk Metallic Glass Composite Coating Surface and Coatings Technology 205 (7) 2010: pp. $1962-1968$. https://doi.org/10.1016/j.surfcoat.2010.08.078

6. Inoue, A., Shen, B.L., Chang, C.T. Super-high Strength of over $4000 \mathrm{MPa}$ for Fe-based Bulk Glassy Alloys in $\left[\left(\mathrm{Fe}_{1-\mathrm{x}} \mathrm{Co}_{\mathrm{x}}\right)_{0.75} \mathrm{~B}_{0.2} \mathrm{Si}_{0.05}\right]_{96} \mathrm{Nb}_{4}$ System Acta Materialia 52 2004: pp. $4093-4099$. https://doi.org/10.1016/j.actamat.2004.05.022

7. Shen, B., Inoue, A. Enhancement of the Fracture Strength and Flass-forming Ability of CoFeTaB Bulk Glassy Alloy Journal of Physics: Condensed Matter 17 (37) 2005: pp. $5647-5654$.

https://doi.org/10.1088/0953-8984/17/37/003

8. Qiu, K.Q., Pang, J., Ren, Y.L., Zhang, H.B., Ma, C.L., Zhang, T. Fe-based Bulk Metallic Glasses with a Larger Supercooled Liquid Region and High Ductility Materials Science and Engineering: A $498(1-2)$ 2008: pp. $464-467$.

https://doi.org/10.1016/j.msea.2008.08.026

9. Inoue, A., Shen, B.L., Koshiba H., Kato, H., Yavari, A.R. Ultra-high Strength Above $5000 \mathrm{MPa}$ and Soft Magnetic Properties of Co-Fe-Ta-B Bulk Glassy Alloys Acta Materialia 52 2004: pp. 1631-1637. https://doi.org/10.1016/j.actamat.2003.12.008

10. Yazici, Z.O., Hitit, A., Yalcin, Y., Ozgul, M. Effects of Minor $\mathrm{Cu}$ and $\mathrm{Si}$ Additions on Glass Forming Ability and Mechanical Properties of Co-Fe-Ta-B Bulk Metallic Glass Metals and Materials International $22(1)$ 2016: pp. 50-57. https://doi.org/10.1007/s12540-016-5220-9

11. Yugeswarana, S., Kobayashi, A. Metallic Glass Coatings Fabricated by Gas Tunnel Type Plasma Spraying Vacuum 110 2014: pp. $177-182$. https://doi.org/10.1016/j.vacuum.2014.04.016

12. Henao, J., Concustell, A., Dosta, S., Cinca, N., Cano, I.G., Guilemany, J.M. Influence of the Substrate on the Formation of Metallic Glass Coatings by Cold Gas Spraying Journal of Thermal Spray Technology 25 (5) 2016: pp. $992-1008$. https://doi.org/10.1007/s11666-016-0419-3

13. Kobayashi, A., Yano, S., Kimura, H., Inoue, A. Mechanical Property of Fe-base Metallic Glass Coating Formed by Gas Tunnel Type Plasma Spraying Surface and Coatings Technology 202 (12) 2008: pp. 2513-2518. https://doi.org/10.1016/j.surfcoat.2007.09.011

14. Zhou, Y.Y, Ma, G.Z., Wang, H.D., Li, G.L., Chen, S.Y., Wang, H.J., Liu, M. Fabrication and Characterization of Supersonic Plasma Sprayed Fe-based Amorphous Metallic Coatings Materials and Design 110 2016: pp. 332-339. https://doi.org/10.1016/j.matdes.2016.08.003

15. Liu, W.D., Liu, K.X., Chen, Q.Y., Wang, J.T., Yan, H.H., Li, X.J. Metallic Glass Coating on Metals Plate by Adjusted Explosive Welding Technique Applied Surface Science 255 2009: pp. $9343-9347$. https://doi.org/10.1016/j.apsusc.2009.07.033.

16. Wang, S.L., Cheng, J.C., Yi, S.H., Ke, L.M. Corrosion Resistance of Fe-based Amorphous Metallic Matrix Coating Fabricated by HVOF Thermal Spraying Transactions of
Nonferrous Metals Society of China

2014: pp. $146-151$.

https://doi.org/10.1016/S1003-6326(14)63040-5

17. Chang, Y.Z., Tsai, P.H., Li, J.B., Lin, H.C., Jang, J.S.C., Li, C., Chen, G.J., Chen, Y.C., Chu, J.P., Liaw, P.K. Zrbased Metallic Glass Thin Film Coating for FatigueProperties Improvement of 7075-T6 Aluminum Alloy Thin Solid Films 544 2013: pp. 331-334. https://doi.org/10.1016/j.tsf.2013.02.104

18. Wu, X.L., Hong, Y.S. Novel Fe70Zr10Ni6Al4Si6B4 Thick Metallic Glass Coating Produced by Laser Cladding Materials Science and Technology $17(8)$ 2001: pp. $1025-1028$. https://doi.org/10.1179/026708301101510906

19. Cheng, J.B., Liang, X.B., Xu, B.S., Wu, Y.X. Characterization of Mechanical Properties of FeCrBSiMnNbY Metallic Glass Coatings Journal of Materials Science 44 (13) 2009: pp. 3356-3363. https://doi.org/10.1007/s10853-009-3436-5

20. Branagan, D.J., Swank, W.D., Haggard, D.C., Fincke, J.R. Wear Resistant Amorphous and Nanocomposite Steel Coatings Metallurgical and Materials Transactions A 32A 2001: pp. 2615-2621. https://doi.org/10.1007/s11661-001-0051-8

21. Pietrowsky, P. Novel Mechanical Device for Producing Rapidly Cooled Metals and Alloys of Uniform Thickness Review of Scientific Instruments 34 (4) 1963: pp. $445-446$. https://doi.org/10.1063/1.1718403

22. Öztürk, P., Hitit, A. Effects of Tungsten and Boron Contents on Crystallization Temperature and Microhardness of Tungsten Based Metallic Glasses Acta Metallurgica Sinica (English Letters) 28 (6) 2015: pp. 733-738. https://doi.org/10.1007/s40195-015-0254-4

23. Yazici, Z.O., Hitit, A. Synthesis of Co-based Metallic Glass Coatings by Pneumatic Squeezing Method Afyon Kocatepe University Journal of Science and Engineering 16 (035702) 2016: pp. $727-733$. https://doi.org/10.5578/fmbd.34254

24. Hitit, A., Öztürk, P., Şahin, H., Aşgın, A.M. Effect of Tungsten Content on Glass Forming Ability and Microhardness of Ni-Cr-B-W Metallic Glasses Journal of Achievements in Materials and Manufacturing Engineering 62 (1) 2014: pp. 5-9.

25. Huang, Z., Wu, L. Ultrahigh-Temperature Ceramics (UHTCs) Systems, In: Phase Equilibria Diagrams of High Temperature Non-oxide Ceramics, Springer Singapore, 2018: pp. $103-165$. https://doi.org/10.1007/978-981-13-0463-7_4

26. Rabinowicz, E. Friction and Wear of Materials, John Wiley and Sons, New York, 1995.

27. Colaço, R. An AFM Study of Single-contact Abrasive Wear: The Rabinowicz Wear Equation Revisited Wear 267 (11) 2009: pp. $1772-1776$. https://doi.org/10.1016/j.wear.2008.12.024

28. Katsuki, F., Tahira, H., Umido, M. Abrasive Wear Behavior of a Pearlitic $(0.4 \%$ C) Steel Microalloyed with Vanadium Wear 264 2008: pp. 331-336. https://doi.org/10.1016/j.wear.2007.03.023

29. Chen, Z., Zhou, K., Lu, X., Lam, Y.C. A Review on the Mechanical Methods for Evaluating Coating Adhesion Acta Mechanica 225 2014: pp. 431-452. https://doi.org/10.1007/s00707-013-0979-y 